\title{
FAILURE OF STERNAL FUSION WITH HERNIATION OF THE PERICARDIUM
}

\author{
BY \\ H. T. THOMPSON \\ From Christchurch Hospital, Christchurch, New Zealand
}

(RECEIVED FOR PUBLICATION MARCH 28, 1961)

Complete failure of sternal fusion is a rare malformation which has been recorded on a number of occasions as being associated with other serious anomalies such as ectopia cordis. Greig (1926) in a study of the literature analysed 39 reported cases of cleft. sternum. In 20 cases varying degrees of cleft sternum occurred without cardiac displacement ; ectopia cordis was present in the other 19. Four cases of thoracic ectopia cordis were reported without sternal cleft. The combined deformity is incompatible with prolonged life. Greig, however, came to the conclusion that in simple cleft sternum the abnormality closely follows the lines of evolution, but with cases of ectopia the sternum may be normal except in so far as the cardiac displacement interferes with its development.

Hanson (1919) has shown that the sternum develops from two laterally situated sternal bands independent of ribs. At the same time a single median anterior rudiment, intimately associated with the shoulder girdle, makes its appearance. The sternal bands approximate with the anterior sternal rudiment on the one hand and the ventrally growing tips of the ribs on the other. The sternal bands themselves then fuse in the midline, beginning at the cranial end at about the eighth week and becoming completely fused by the end of the ninth week. It is the failure of this sternal fusion that produces the deformity under discussion.

Surgical repair of the deformity has been recorded on several occasions (Burton, 1947 ; Maier and Bortone, 1949 ; Longino and Jewett, 1955 ; Asp and Sulamaa, 1960). Although in some cases the cleft sternum was reported to be associated with ectopia cordis, most if not all seem to be primarily a failure of sternal fusion.

\section{CASE History}

N.E., a boy, was admitted to the Christchurch Hospital on October 1, 1959, at the age of 10 days. The child was in no distress, but it had been noted soon after birth that there was paradoxical movement over the anterior part of the chest wall. This was associated with separation of the lateral bars of the sternum over almost its whole length. When the child cried the intrathoracic contents protruded alarmingly through the cleft. The only other abnormality was a midline dermal defect having a scar-like appearance and situated in the epigastric region. (This feature was also noted in Maier and Bortone's case and was mentioned by Greig.)

An operation to correct the deformity was carried out on October 2. Endotracheal anaesthesia with nitrous oxide and intermittent scoline was used and cyclopropane in the closing stages. Through a vertical midline incision from the lower cervical region to the epigastrium, the pericardium was dissected off the outer surface of the chest wall and the margins of the sternal defect. This revealed a wide horseshoe-shaped sternal deformity through which pericardium protruded below and thymus above.

It was found impossible to approximate the sternal elements by pressure, and it seemed that neither partial transection (Maier) nor complete transection (Longino) of the sternal bars in the fourth or fifth intercostal spaces would be satisfactory. Separation of the sternal bars was completed by subperichondrial excision of a segment $1.5 \mathrm{~cm}$. wide from the apex of the horseshoe. Thereafter the sternal bars came together without undue tension. Approximation was maintained with interrupted thread sutures through the perichondrium, which had been raised from the margins of the sternal defect. A small drain was placed beneath the lower end of the sternum and brought through the stab incision in the abdominal wall. The pectoral fascia and skin were closed in layers with interrupted sutures.

Post-operative progress was uneventful, and the patient was discharged from hospital 48 hours later. 
When seen 15 months later the child had made satisfactory progress since operation. He had a normal chest contour and there was no clinical evidence of a sternal cleft.

\section{Discussion}

Maier and Bortone have emphasized the necessity for early operation in these cases. Their own patient, seen two weeks after birth but not operated on till the age of 7 weeks, showed a change in the shape of the deformity at that time, with a widening of the cervical end of the gap. They considered that this was due to the weight of the shoulder girdles acting through the clavicles, the child having been nursed on its back.

In the present case the U-shaped deformity was such that, at the age of 10 days, the procedures advocated by Maier and Bortone or by Longino and Jewett were not adequate to deal with it. The removal of a segment from the apex of the horseshoe did not appear to cause compression of the intrathoracic contents or interfere with cardiac action.
Recently Asp and Sulamaa (1960), in reporting on a patient, who was 2 months old at operation, used staged bone grafts taken from the skull to fill the defect. Burton (1947), in reporting two cases of operative correction of this deformity, used a free graft of cartilage to cover the otherwise unprotected heart.

\section{SUMMARY}

A case of failure of sternal fusion with prolapse of pericardium is presented. The embryological development of the sternum and its relationship to ectopia cordis is reviewed briefly. The correction of the deformity is discussed and a method of repair presented.

\section{REFERENCES}

Asp, K., and Sulamaa, M. (1960). Acta chir. scand., 118, 392. Burton, J. F. (1947). Arch. Surg. (Chicago), 54, 79.

Greig, D. M. (1926). Edinb. med. J., n.s., 33, 480.

Hanson, F. B. (1919). Amer. Anat., 26, 41.

Longino, L. A., and Jewett, T. C. (1955). Surgery, 38, 610.

Maier, H. C., and Bortone, F. (1949). J. thorac. Surg., 18, 851. 